\title{
UN CONFLICTO BÁSICO DE LA VIDA MORAL
}

\section{La vigencia de las normas morales y su limitación}

Todo estudio ético del comportamiento humano presupone en éste alguna forma de normatividad. La expresión "vida moral" alude siempre a con. ductas regidas por determinadas normas. Se dice que un hombre es "moral" cuando obra "por principios", que es "inmoral" cuando contradice o contraviene sus propios principios, y que es "amoral" cuando carece de principios. También se presupone, por cierto, la libertad del agente frente a las exigencias contenidas en las normas, o sea, el hecho de que éstas pueden cumplirse o contravenirse; pero ellas constituyen, en todo caso, el necesario punto de referencia.

La "vida moral" se entiende, pues, como vida normativa. Sin embargo, es indiscutible el hecho de que las normas están sometidas a variaciones espacio-temporales, o sea, de que ellas difieren según las épocas y según las comunidades culturales o los grupos humanos, e incluso según los individuos. Más aún: se pueden señalar variaciones en los distintos momentos de la vida de un mismo individuo. Esta historicidad de las normas parece'contradecir la intención de universalidad que, en mayor o menor medida, reside en cada una de ellas. El contenido de una norma no puede reducir su pretensión de validez a una circunstancia determinada, ya que tal reducción le sustraería justamente su carácter de principio regulador de la conducta. La limitación fáctica de la vigencia de cada norma da lugar, de este modo, a una curiosa paradoja, y, en definitiva, a uno de los problemas capitales de la ética.

Veamos, ante todo, cómo hay que entender esa "limitación fáctica de la vigencia". Por un lado, es obvio que la vigencia de una norma moral no depende de su cumplimiento irrestricto por parte de los agentes morales para quienes se supone que ella "rige". El asesinato, por ejemplo, no anula, sino que más bien confirma la norma que ordena "no matar". Y no la confirma meramente en el sentido de una "excepción" que "confirma la regla", sino que lo confirmado pertenece aquí al "deber ser". No siempre "es" (de facto) lo que "debe ser" (de jure), e incluso es pensable que justamente la coincidencia entre el "ser" y el "deber ser" resulte lo "excepcional". Para la vigencia de una norma moral basta la suposición de que "se debe" obrar de una determinada manera, aunque de hecho no se obre así. Esto es precisamente lo que distingue a la ley moral de la ley natural. La vigencia de esta última se anula conforme aparece un fenómeno que no la cumple. La ley moral, en cambio, se basa en la libertad humana y por tanto lleva implícita la posibilidad de su no-cumplimiento. 
¿Hasta qué punto, sin embargo, puede sostenerse la independencia de la vigencia de una norma moral con respecto a la actitud que tienen de hecho hacia ella los respectivos agentes morales? "Vigencia" significa aquí un modo de reconocimiento (que, como tal, no es ya de jure, sino de facto). Aunque los agentes morales no "cumplan" una determinada norma, sólo se puede decir que ésta es "vigente" si aquellos la "reconocen" como válida, es decir, si "creen" en ella. Al margen, entonces, de que una tal actitud de afirmación no puede dejar de reflejarse en la acción ( $y$ vincula, por tanto, la "vigencia" con el "cumplimiento"), ocurre que, en cuanto actitud, es por sí misma una manifestación de la vida práctica de los mencionados agentes. También este aspecto constituye un criterio de distinción entre ley moral y ley natural. La vigencia de la ley natural es absolutamente independiente del "consenso" de aquellos para quienes ella rige. La de la ley moral, por el contrario, alude de algún modo a ese consenso, ya que está referida a su aceptación, a su "reconocimiento" por parte de los agentes morales.

Como corolario de lo anterior podría decirse que, en un primer sentido, la "limitación fáctica de la vigencia", en cualquier norma moral, designa el minimo grado de reconocimiento alcanzado de hecho por esa norma. Es evidente que el reconocimiento de una norma puede ser más o menos intenso. Donde una norma moral tiene tendencia a cumplirse siempre, y su no cumplimiento acarrea graves conflictos de conciencia o un profundo arrepentimiento, etc., puede decirse que esa norma tiene una gran intensidad de vigencia. La intensidad será, por el contrario, débil o escasa, si la norma es reconocida meramente por hábito, sin una honda convicción de su validez. Esto se distingue, sin embargo, de una intensidad nula, como ocurre con una norma que no es reconocida como tal. Debe haber, por tanto, un punto de transición entre el reconocimiento y el no reconocimiento, o sea, un limite de la vigencia en lo que respecta a la intensidad.

Pero hay también un segundo sentido de la "limitación fáctica de la vigencia", que no alude a la intensidad, sino a la extensión de la misma. Cuando se habla de la "variabilidad" de las normas $\longrightarrow$, como se ha hecho especialmente en la ética contemporánea, de "revolución del ethos"-_ se está mencionando el hecho, empíricamente comprobable, de que las normas sólo tienen una vigencia limitada a un determinado ámbito espacio-temporal. Unas normas podrán extender su vigencia a más agentes morales que otras, es decir, podrán ser reconocidas por una mayor cantidad de individuos o grupos humanos, o durante un periodo de tiempo más prolongado; pero ninguna llegará a contar con el reconocimiento de todos los agentes morales posibles.

Conviene tener en cuenta que las variaciones de la intensidad son independientes de las variaciones de la extensión. No ocurre aqui lo que en la comprehensión (o "intención") y la extensión lógicas de un concepto, que mantienen una relación de proporcionalidad inversa. Hay normas de vigen- 
cia muy extensa y muy intensa (como la de "no matar"), de vigencia muy extensa y poco intensa (como la de "no mentir"), de vigencia poco extensa y muy intensa (como la de los mahometanos de no comer carne de cerdo, o la de los hindúes de no comer carne de vaca), y de vigencia poco extensa y poco intensa (como ciertas formas de la cortesía).

La contraposición entre la intención de universalidad (o al menos de validez objetiva) de las normas y la limitación fáctica de la vigencia de las mismas se pone de manifiesto cada vez que se trata de determinar su aplicabilidad a una circunstancia concreta. La exigencia de universalidad no atiende a las diferencias entre las circunstancias. La convicción de que la vigencia está siempre limitada pone el acento, en cambio, en esas diferencias. La limitación es obvia; pero la ubicación precisa de los límites es siempre algo discutible. Es cierto que la aplicabilidad no se identifica con la vigencia; pero, por lo pronto, la presupone: si hay acuerdo acerca de la no vigencia de una determinada norma, no podrá suscitarse ninguna discusión acerca de si la misma es o no aplicable en tal circunstancia. Si, por el contrario, existe un desacuerdo acerca de la vigencia, también podrá haberlo acerca de la aplicabilidad. Las limitaciones de la vigencia son, en tal sentido, ocasión para permanentes cuestionamientos de la aplicabilidad.

Desde luego, también puede ocurrir, y ocurre efectivamente con frecuencia, que se esté de acuerdo acerca de la vigencia de una determinada norma y, sin embargo, se discrepe acerca de si ella es o no aplicable hic et nunc, es decir, en tal o cual circunstancia particular. Alguien puede aceptar, por ejemplo, la vigencia de la norma "no matar" pero sostener, a la vez, que, en circunstancias de guerra, esa norma no es aplicable frente al enemigo. Por otra parte, sin embargo, la aparición de numerosas circunstancias en las que, de modo semejante, se cuestione la aplicabilidad, puede a su vez llevar a dudas acerca de la vigencia. Si todas las circunstancias constituyen "excepciones", o sea, si cada "caso" se convierte en una nueva "situación" imprevisible, parece perderse el sentido mismo de la vigencia. Se tiende entonces a interpretar la exigencia de universalidad como una pretensión totalmente infundada. Si, como vimos, la aplicabilidad presupone la vigencia, también la vigencia presupone aplicabilidad. Aunque se trata, pues, de aspectos no identificables, hay entre ellos una mutua implicación.

El problema ético que todo esto suscita no es una arbitraria construcción de los filósofos, sino una cuestión que se plantea permanentemente en las relaciones interculturales, interpersonales e incluso intrapersonales. La normatividad de la conducta es ya, por sí misma, de naturaleza problemática, en el sentido de que, aun aceptándosela, se puede discrepar acerca del tipo de normas que determinan la "moralidad" de los actos (y es así como surgen las posiciones religiosas, deontológicas, utilitaristas, axiológicas, etc.). Pero la problematicidad es tanto más radical cuando la normatividad se enfrenta 
con la limitación fáctica de la vigencia de todo tipo de normas. La necesidad dë afirmar la normatividad (y la exigencia de universalidad implícita en ésta) lleva a interpretar cada circunstancia concreta como un "caso" que, de algún modo, ha de estar previsto en alguna norma vigente. La necesidad de afirmar la limitación fáctica de la vigencia, en cambio, lleva a acentuar el carácter contingente de las circunstancias concretas, $\mathrm{y}$, por tanto, a considerarlas como "situaciones" singulares e irrepetibles, o sea, imprevistas e imprevisibles. Toda la vida moral está atravesada por ese conflicto básico, que, desde un punto de vista lógico, parece una contradicción: las circunstancias morales concretas son, simultáneamente, previsibles e imprevisibles, "regulares" e "irregulares". La previsibilidad refleja el carácter "normativo" de la conducta; la imprevisibilidad es la consecuencia del carácter "histórico" de las nörmas. La regularidad permite aplicar los principios morales vigentes; la irregularidad se deriva de la limitación fáctica de la vigencia (que es también, en definitiva y por lo ya apuntado, limitación fáctica de la aplicabilidad).

Una manera de eliminar esta paradoja consiste en la adhesión incondicional a uno de los términos del conflicto (y en la consecuente negación del otro). Es así, por lo pronto, como surgen dos posiciones diametralmente opuestas: la del "casuismo" y la del "situacionismo".

\section{Casuismo y situacionismo}

El "casuismo" no es sino la exageración de la casuistica, y ésta constituye por su parte un conjunto de reglas para la aplicación de un determinado sistema normativo (de orden jurídico, moral, teológico, etc.) que se presupone como válido. En el ámbito moral, la casuística se basa en un sistema de normas morales y en la convicción de que esas normas pueden aplicarse a toda circunstancia posible, es decir -y de allí su denominación-, a todo "caso". Cobra importancia especialmente en aquellos casos de aplicabilidad dudosa, como los conflictos entre exigencias diversas. Si se pasan por alto los elementos casuisticos que pueden hallarse en algunas doctrinas éticas orientales (budismo, confucionismo), se puede sostener que la casuística se introduce a la reflexión moral con la ética del estoicismo. Se halla también, desde luego, en la moral dependiente de la religión judía, centrada en la rigurosidad de sus leyes, y en la teología moral católica, donde designa la decisión de "casos de conciencia" a partir de los Mandamientos. Estos se conciben, pues, como el código moral fijo y de validez absoluta, por referencia al cual serfan solubles todos los posibles conflictos. Tal concepción, a su vez, presupone la tipificabilidad de los conflictos, y de hecho va acompañada por una minuciosa y compleja clasificación de los mismos. A comienzos de la Edad Media, la casuística representaba un recurso auxiliar, con el que el clero de escasa formación cientifica podía resolver los "casos" difíciles que se le presentaban 
en la confesión. La escolástica se ocupó también de la casuística; pero ésta obtuvo su importancia máxima en los siglos xvir y xvir, con el auge del jesuitismo. Ya en esa época, sin embargo, fue a su vez enérgicamente combatida, no sólo desde el protestantismo, sino también desde corrientes que se hallaban dentro de la Iglesia Católica, como el jansenismo. Subsiste, sin embargo, en épocas posteriores, e incluso en el siglo actual, en teólogos como F. Tillmann y otros.

Las concepciones éticas con clara conciencia de la conflictividad, por el contrario, rechazan necesariamente la casuística, y sobre todo el "casuismo". Dewey, por ejemplo, reconoce que la ética puede intentar clasificaciones generales de los conflictos, que permitan a la gente moral ubicar su problema particular en un contexto mayor, y puede también sugerir determinadas alternativas (basadas en la reflexión sistemática). "Pero no puede -agrega Dewey - presentar un cuadro de mandamientos en un catecismo en el que las respuestas sean tan definidas como las preguntas que se hacen. Puede hacer más inteligente la elección personal, pero no puede tomar el lugar de la decisión personal a que debe llegarse en todo caso de perplejidad moral. (...) La conclusión deriva de la naturaleza misma de la moralidad reflexiva; el intento de fijar conclusiones preestablecidas contradice la naturaleza misma de la moralidad reflexiva". ${ }^{\text {El }}$ El mismo pensador indica que la casuística se ve obligada, para prever "todos" los casos posibles, a complejísimas clasificaciones, catalogaciones, encasillamientos, etc., del sinfín de situaciones en que puede producirse la contravención a una determinada norma, y del grado de culpabilidad o inocencia que corresponde a cada una de las circunstancias, para lo cual a su vez es preciso clasificar también "todos" los posibles impulsos que determinan la acción, etc. Todo esto tiene, según Dewey, los siguientes inconvenientes: 1) se atiende más a la "letra" que al "espiritu" de la moralidad (ello da lugar, por un lado, al desarrollo de una sofística destinada a justificar los propios intereses, y, por otro, a imbuir la conducta moral de rigidez y pedantería, como ha ocurrido con el fariseismo y el puritanismo); 2) se introduce el primado de la "legalidad" en la conducta moral (las cuestiones del castigo o la recompensa según la sujeción al "mandato de la ley" pasan o ocupar el primer plano), y 3 ) se tiende a privar de libertad y espontaneidad a la vida moral (se acentúa la heteronomía moral; las reglas morales externas son vistas como mandatos que exigen obediencia incondicional). ${ }^{2}$ También Croce se opone a los procedimientos casuísticos, porque piensa que las reglas fijas no ofrecen soluciones concretas. Tales reglas y raciocinios casuisticos conducen, según él, a tremendos errores: "Los que sobre las cosas prácticas razonan de antemano, distinguiendo sutilmente lo que

1 J. Dewey, Teoria de la vida moral, trad. R. Castillo Dibildox, México, Herrero Hnos., 1965 , p. 26.

2 Cfr. ibid., pp. $164^{-166 .}$ 
hay que evitar en el mundo de los negocios y en el mundo de la acción, si no han preparado todavía algún desastre, es probable que lo estén preparando. $Y$ ésta, por lo menos, es una buena regla, como la regla suprema (la cual ya no es regla, sino verdad filosófica) es salirse de las reglas, esto es, afrontar el caso individual, que como tal es siempre irregular". ${ }^{3}$ El rechazo de la casuistica, en términos similares a los de Dewey o Croce, aparece también en la Etica de Nicolai Hartmann, pese a tratarse aquí de una filosofía alejada del pensamiento "pragmatista" de aquellos. Según Hartmann, la ética tiene que tratar de responder - aun a sabiendas de que tropieza aquí con una "aporía" - la pregunta por el "qué se debe hacer". La respuesta que ella proporcione, sin embargo, no podrá referirse a lo que debe hacerse hic et nunc, es dëcir, en una situación concreta, sino que ofrecerá, a lo sumo, un panorama sobre la configuración general del deber-hacer." De acuerdo con esta concepción, la ética no determina ni define el "que" propiamente dicho del deber, sino que busca criterios para el reconocimiento general de lo que el deber significa. Toma "distancia" con respecto a los "casos" particulares; no para "desprenderse" de ellos, sino para ofrecer sobre ellos una especie de vista de conjunto, "a vuelo de pájaro". La ética, dice Hartmann, "no se inmiscuye en los conflictos de la vida, ni da preceptos referentes a ellos; no es un código de mandamientos y prohibiciones, como ocurre con el Derecho. Se dirige justamente a lo que hay de creador en el hombre, desafiándolo a que perciba, o por así decir, a que adivine, en cada nuevo caso, lo que debe ocurrir aquí y ahora. La ética filosófica no es casuística, y jamás le es licito convertirse en algo semejante: con ello mataría en el hombre justamente aquello que debiera despertar y educar: lo creador, lo espontáneo, el intimo contacto viviente del hombre con lo que debe ser, con lo valioso en si". ${ }^{5}$ Nowell-Smith, por su parte, escribe en su Ética: "Las preguntas '¿qué debo hacer?' y '¿qué principios morales debería yo adoptar?' tienen que ser cuntestadas por cada uno por si mismo. Esto, en definitiva, es parte de la connotación de la palabra "moral" ". ${ }^{\circ}$

Otros filósofos, en cambio, entienden que no debe hacerse una distinción tan radical entre "ética" y "casuística". G. E. Moore, por ejemplo, incluye a ésta dentro de aquella. Por cierto, también él advierte que la ética no puede ocuparse con hechos que son únicos y absolutamente particulares, e incluso admite que "no es asunto del filósofo de la ética hacer advertencias o exhortaciones personales".7 Pero, al mismo tiempo, observa que juicios del

3 B. Croce, Filosofía práctica en sus aspectos económico y ético, trad. E. González Blanco; Buenos Aires, Anaconda, 1942, p. 20.

4 Cfr. N. Hartmann, Ethik, Berlín, W. de Gruyter, 4e. Aufl, 1962, Einleitung, §2, pp. 3*5.

5 Ibid., p. 4.

6 P. H. Nowell-Smith, Ethics, Oxford, B. Blackwell, 1957, p. 278.

7 G. E. Moore, Principia Ethica, trad. A. Garcia Diaz, Universidad Nacional Autónoma de México, 1959, p. 3. 
tipo de "el placer es bueno", o que enumeran las distintas "virtudes", forman la sustancia propia del estudio de la casuística. 'Se nos podrá decir -escribe Moore- que la casuística difiere de la ética, en que la primera es mucho más detallada y particular, y la segunda más general. Pero es muy importante advertir que la casuística no se ocupa con nada que sea absolutamente particular - particular en el único sentido en que puede trazarse una perfecta y precisa línea entre lo particular y lo general. (...) La casuistica puede, con seguridad, ser más particular, y la ética más general; pero eso significa que difieren sólo en grado y no en género". ${ }^{8}$ La casuística así entendida es una disciplina que se ocupa de lo general, aun cuando trate también de descubrir, por ejemplo, los méritos relativos en cada forma distinta en que puede presentarse una determinada virtud. Los "defectos" de esta disciplina, según Moore, no lo son "de principio", sino que obedecen a las dificultades propias de su tema. Hay que distinguir, entonces, entre sus "errores", que deben tratar de superarse, y su meta, que debe conservarse, porque es la misma de toda investigación ética. ${ }^{\circ}$ Hans Reiner, por su parte, afirma, "la posibilidad y la necesidad de una casuistica de las exigencias morales", ${ }^{10}$ teniendo en cuenta los "principios racionales" que pueden servir como criterios de preferencia axiológica; pero agrega que esa casuística deja también un margen de posibilidades libres e imprevisibles, determinadas por un principio irracional, intuitivo ("principio del daimon").

La posición contraria a la casuística (y sobre todo al "casuismo") es, como dijimos, la del "situacionismo", actitud que, con respecto a las cuestiones morales, está representada especialmente por la "ética situacional". Ésta aparece de manera expresa sólo en la filosofía contemporánea, y de modo particular en la "filosofía de la existencia". Hay, sin embargo, decisivos rasgos de ética situacional ya en algunos estoicos heterodoxos, como Herilo y Aristón, discípulos de Zenón de Citium, pero apartados luego de las doctrinas del maestro. En líneas generales, la ética situacional sostiene que ninguna norma puede prever todas las situaciones, y esta afirmación le sirve como premisa para inferir que la decisión moral depende exclusivamente de cada situación concreta. La circunstancia en que se obra no es interpretada, por tanto, como un "caso" regulable y ubicable en un esquema trazado de antemano, sino como una "situación" siempre nueva e irrepetible, en la que no puede contarse con criterios generales. Esto no significa, sin embargo, una negación de la moralidad: la ética situacional es, justamente, una ética, $\mathrm{y}$, en tal medida, un intento de ofrecer criterios de distinción entre el obrar mo-

\footnotetext{
8 Ibid., pp. 3-4.

9 Cfr., ibid., p. 4 .

10 H. Reiner, Pflicht und Neigung. Die Grundlagen der Sittlichkeit; Meisenheim a. Glan, A. Hain, 1951, p. 174. Cfr., del mismo autor: Das Prinzip von Gut und Böse; Freiburg i. Br., K. Alber, 1949, p. 20.
} 
ralmente bueno y el malo. Sólo que tales criterios no pueden, para ella, estar constituidos por normas de validez universal. El criterio tiene que surgir exclusivamente de cada situación particular, y por tal motivo se excluye todo "sistema".

En nuestra época, los representantes declarados de la "ética situacional" se encuentran especialmente en algunas direcciones de la teología (más en la protestante que en la católica). Aquí ha sido decisiva la influencia de Kierkegaard, aunque es discutible que dicha ética derive exclusivamente de este pensador, como así también que él mismo haya sido exclusivamente un "situacionista"."11 Kierkegaard quería, sobre todo, "salvar" al individuo frente a la abstracción de la metafísica hegeliana, que tendía a convertirlo en una mera expresión de lo universal, donde quedaba prácticamente disuelto. Su reacción consiste en acentuar la importancia del instante, en el cual una existencia humana personal se halla frente a un Dios personal. Con su concepto de "categoría existencial" (que determina el carácter histórico de la libertad), aplicado al plano o "estadio" ético —o sea, como elección, culpa, arrepentimiento, etc.-, indica Kierkegaard que la libertad es siempre precaria y expuesta al peligro. Lo "ético", en sí mismo, es lo "general"; pero desde allí es posible el "salto cualitativo" a lo "religioso", ámbito supremo de la existencia, donde el instante, en cuanto "categoria existencial" - junto a otras como el pecado, la bienaventuranza, la fe, etc.- desempeña un papel decisivo: ${ }^{12}$

En algunos teólogos protestantes contemporáneos la ética situacional se conecta con la afirmación de la individualidad de la existencia, en la cual la situación (concebida como un hecho entitativo y estructuralmente irrepetible) representa un llamado y una iluminación de Dios al individuo, una especie de revelación personal de lo que constituye el deber concreto en el momento concreto: ${ }^{13}$ Karl Barth es, en este ámbito, uno de los representantes más célebres. Cuestiona especialmente la pretensión de validez universal en las normas éticas, y esgrime, contra el "imperativo categórico" kantiano, el "mandamiento" divino dirigido al hombre en una situación determinada. ${ }^{14}$

Entre los teólogos católicos hay también quienes, como T. Steinbüchel, ${ }^{15}$

11 Cfr., al respecto, H. J. Martensen, "Kierkegaard und die Situationsethik", en Scholastik 26 (1951), pp. $55^{6}$ ss.

12 Cfr., sobre este problema: A. Pieper, "Die Bedeutung des Begriffs 'Existenzkategorie' im Denken Kierkegaards", en: Zeitschrift für philosophische Forschung, 26 (1971), pp. 187 ss.

13 Cfr., por ejemplo, la obra de E. Brunner, Das Gebet und die Ordnungen. Entwurf einer protestantischen Ethik, Tübingen, 1932. Del mismo autor: Glaube und Ethik, Thun, W. Krebser, 1945.

14 Cfr. K. Barth, Christliche Dogmatik, II, 2, pp. 743 ss.

15 Cfr. T. Steinbüchel, Christliche Lebenshaltungen in der Krisis der Zeit und des Menschen, Frankfurt a. M., 1949. Del mismo autor: "Die philosophische Grundlegung der katholischen Sittenlehre", en F. Tillmann (Hersg.): Handbuch der katholischen Sittenlehre, Düsseldorf, 1951, Bd. I, 1.-2. Halbband. 
Ernst Michel, ${ }^{16} \mathrm{~W}$. Dirks ${ }^{17}$ y otros, se aproximan a la ética situacional, aunque por cierto con mayor cautela que los protestantes. En los católicos, por lo general, no se niega la validez universal, sino que se ponen ciertos reparos frente a la capacidad de la ley objetiva universal para abarcar la compleja individualidad de cada situación concreta. Es decir, se intentan trazar ciertos límítes, más allá de los cuales los preceptos tienen que dejar un margen a la libre deliberación del individuo. Lo más frecuente, de todos modos, es que, desde la teología católica, se ejerza una crítica a la "ética situacional". Un buen ejemplo puede encontrarse en Joseph Fuchs. ${ }^{18}$

La filosofía existencial renovó y amplificó la importancia de la situación, que había sido ya destacada por la "filosofía de la vida". ${ }^{19}$ Entre los pensadores de la "existencia" es frecuente, por cierto, un decidido rechazo de la ética, lo cual hace discutible que se pueda hablar, con respecto a ellos, de "ética situacional". Pero, por otro lado, las coincidencias con ésta son tan evidentes, que resulta imposible no vincularla con dichos pensadores. La acentuación de la libertad convierte, de hecho, a la "existencia" misma en una praxis moral. ${ }^{20}$ Como lo observa Aranguren, "entre la filosofia de la existencia y la ética de la situación hay un evidente paralelismo: el existencialismo rechaza una esencia anterior a la existencia; no hay más esencia que la esencia concreta conquistada por cada libertad existencial, existiendo. Análogamente, la ética de la situación rechaza una norma anterior a la situación; no hay más norma que la norma concreta hallada desde dentro de cada situación única viviéndola". ${ }^{21}$ Como ejemplo clásico del "situacionismo" ético del pensamiento existencial suele citarse el pasaje donde Sartre,

16 Cf. E. Michel, Glaubige Existenz, 1952.

17 Cfr. W. Dirks, "Wie erkenne ich, was Gott von mir will? Zur Berechtigung einer Situationsethik", en: Frankfurter Hefte, 1951, Heft 6, pp. 229 ss. También W. Dirks y B. Hansler: Der neue Humanismus und das Christentum; München, 1968.

18 Cfr. J. Fuchs: Situation und Entscheidung. Grundfragen christlicher Situationsethik, Frankfurt a. M., J. Knecht, 1952, obra critica, que en parte, admite también elementos "situacionales". Otro buen ejemplo de este tipo de crítica es el articulo de J. Stallmach: "Das Problem sittlicher Eigengesetzlichkeit des Individuums in der philosophischen Ethik", en: Theologie und Philosophie, 42 (1967), Heft 1, pp. 22-5o.

19 Hace notar Bollnow que el concepto de "situación" (Situation) usado por los filósofos de la existencia, equivale, en líneas generales, al de "posición" (Lage), corriente entre los representantes de la "filosofía de la vida". Se distinguen, sin embargo, en que la "Situation" existencial destaca el carácter de "urgencia" y de "estrechura", en tanto que la "Lage" vital se entendía más bien como estado de calma (Ruhelage), como disposición en que el hombre se encuentra. Cfr. O. F. Bollnow: Existenzphilosophie; Stuttgart, W. Kohlhammer, 42. Aufl., 1955, pp. 58-59. Del mismo autor: Filosofía de la esperanza. El problema de la superación del existencialismo (trad. A. Orías Medina); Buenos Aires, Compañla General Fabril Editora, 1962; cf., especialmente Primera Parte, pp. 35 ss.

20 Acerca de esta aproximación entre los conceptos morales y existenciales por su mutua referencia a la libertad, cf. A. Pieper: Sprachanalytische Ethik und praktische Freiheit. Das Problem der Ethik als autonomer Wissenschaft; Stuttgart, W. Kohlammer, 1973, pp. 214 ss. También O. F. Bollnow: Französischer Existentialismus; Stuttgart, 1965, pp. 53 ss. 21 J. L. L. Aranguren: Etica; Madrid, Rev. de Occidente, $3^{g}$ ed., 1965; pp. 275. 
en El existencialismo es un humanismo, relata el caso de aquel joven que, durante la ocupación nazi en Francia, dudaba entre ir a Inglaterra a alistarse en las Fuerzas Francesas Libres o quedarse en Francia junto a su madre sola y enferma. Al solicitar el consejo de Sartre, éste le había contestado: "Elija, es decir, invente. Ninguna moral general puede dictarle lo que ha de hacer." 22 Esto indica que se concibe la acción moral simplemente como aquella que deriva de una elección libremente asumida. Tal concepción desemboca a su vez en una peculiar axiología, ya sugerida por el propio Sartre ${ }^{23}$ pero desarrollada especialmente por Raymond Polin, ${ }^{24}$ en la que el valor aparece como una "creación" o "invención" irreal de la conciencia (ligada siempre, por su parte, a una determinada situación).

Una explícita y extrema afirmación de la ética situacional se halla en la filosofía de Eberhard Grisebach, quien recibió influencias de Jaspers y del teólogo Gogarten. Para Grisebach, el hombre está indisolublemente ligado a su "presente" (Gegenwart), el que, a su vez, se halla en flujo o cambio permanente. Siendo la "situación" distinta en cada nueva circunstancia, no puede jamás preverse de antemano, $y$, por tanto, no puede haber normas generales "válidas" por las cuales regir la conducta: toda suposición de que la reflexión o la "intuición de esencias" puedan proporcionar algún sistema decisivo para la vida en el "presente" constituye una auto-ilusión. ${ }^{25} \mathrm{El}$ hombre concreto, real, se encuentra, en cada instante, en una situación concreta en la que tiene también que tomar una decisión concreta, para la cual no cuenta con recetas generales que se hallen fuera de él o de su "presente" concreto. La "ética critica" de Grisebach está dirigida contra todas las que el llama "éticas dogmáticas", es decir, contra todos los supuestos normativos que desconocen la condición fundamental del obrar humano, constituida por la sujeción al "presente". Éste no puede inferirse del pasado: los "recuerdos" no ofrecen criterios para la experiencia, que es siempre nueva.

También la ética de Georges Gusdorf presenta carácter "situacional", pero se trata, en todo caso, de un "situacionismo" relativo y mitigado. En él se considera la "existencia moral" como un factum que debe captarse sin

22 J. P. Sartre: Liexistentialisme est un humanisme; Paris, 1946, p. 47. Sobre la "ética" sartriana cf. F. Jeanson: Le probleme morale et la pensée de Sartre; Paris. Ed. du Seuil, 1965 , especialm. pp. 265 ss.

23 Cfr. J. P. Sartre, El ser y la nada. Ensayo de ontologia fenomenologica; trad. Juan Valmar, Buenos Aires, Losada, 1966 , particularmente $1^{\text {a }}$ Parte, cap. I, pp. $4^{1}$ ss., $2^{\text {a }}$ Parte, cap. I, § III, pp. 149 ss., $4^{\text {a }}$ Parte, cap. I, pp. 537 ss., y Conclusión, pp. $74^{8 s s .}$

24 Cfr. R. Polin, La création des valeurs, Paris, P. U. F., 2a éd., 1952; La compréhension des valeurs, Paris, P.U.F., 1945; Du laid, du mal, du faux, Paris, P.U.F., 1948. Véase también su artículo "Subjectivisme des valeurs et réflexion morale", en: Actes du HIe. Congrés des Soc. de Langue Française (Bruxelles-Louvain 1947) ed. Louvain-Paris, 1948, pp. 183 ss.

25 Cfr. E. Grisebach, Gegenwart. Eine kritische Ethik; Halle-Saale, M. Niemeyer, 1928; p. 192. 
abstraer la situación en que está siempre colocado el hombre. Gusdorf propone una "moral concreta", para el hombre entendido en su particular situación, y desde la cual se entienda la libertad no como la "autonomía" de una "razón triunfante", sino como la "libertad de una existencia combatiente y sufriente, abandonada a sí misma y al mundo". ${ }^{26}$ La afirmación de reglas generales e incorruptibles es, según Gusdorf, propia del estilo "serio" de la vida, en el cual la existencia se subordina a un "dominio de la uniformidad". ${ }^{27}$ Con esto se pierde el verdadero sentido de la existencia humana, que es concreta y temporal. Sin embargo, también es errónea la vida vivida para el placer y la aventura, es decir, la vida desde el instante y para el instante, la cual elige el presente y lo desprende de toda vinculación con el pasado y con el futuro. Si la actitud "seria" está atada a las reglas, esta otra -que Gusdorf llama "esteticista" - se disgrega en la discontinuidad; intenta destemporalizar el acontecer temporal en sí mismo, y de ese modo pierde también el sentido de la existencia: ésta se experimenta, en definitiva, como un absurdo. EI hombre "verdaderamente moral", en cambio, es para Gusdorf aquel que "acepta el reino del tiempo, el peso del pasado, el llamado del futuro, la plenitud del presente". ${ }^{28}$ Entre el estilo "serio" (o de "intemporalidad") y el estilo "esteticista" (o del instante), hay, pues, según Gusdorf, un tercer estilo posible: el de la vida "espiritual" (o de la eternidad), que representa una síntesis de lo abstracto y lo concreto, de lo universal y lo particular. Sólo en este estilo puede el hombre alcanzar su propia unidad personal.

"Casuismo" y "situacionismo" son, en definitiva, expresiones de dos tendencias opuestas: una dirigida a prefijar el carácter "moral" o "inmoral" de toda decisión, y otra dirigida a imposibilitar la determinación de tal carácter. Pero son, justamente, tendencias, direcciones, que nunca llegan totalmente a los extremos opuestos a que apuntan, porque alli se tornan insostenibles. El "casuismo" extremo, como vimos, está rechazado incluso por quienes, como Moore o Reiner, admiten, dentro de ciertos límites, la licitud de una "casuística". El puro "situacionismo" o "actualismo", que desvincula totalmente cada situación de todas las demás, es sometido a crítica también por pensadores que, como Gusdorf, afirman el carácter "situacional" de la existencia moral. El contraste entre esos dos extremos puede resumirse como lo hace Aranguren: "La ética de la situación considera absolutamente indeterminable de antemano lo que ha de hacerse en la singularidad de cada circunstancia concreta. El casuismo (...), al revés, pretende prever todas las situaciones posibles y predeterminar lo que en cada una de ellas ha de hacerse $u$ omitirse. Para la ética de la situación la conciencia tiene que 'inventar' en cada caso la decisión; el casuismo quisiera tener 'dictadas' a la conciencia,

26 G. Gusdorf, Traité de l'existence morale, Paris, A. Colin, 1949, p. 41.

27 Cfr., ibid., p. 169 .

28 Ibid., p. 187 . 
de antemano, todas las decisiones que ésta ha de tomar. Para la ética de la situación la 'regla' no sirve de nada o casi nada; el casuismo, por el contrario, pretende 'regular' la vida entera." 20

La antinomia de la conducta normativa cobra de este modo una nueva dimensión. Las posiciones extremas, al eliminar uno de los términos, aparentan suprimir también la antinomia misma, pero incurren así en una desmesura impugnable, que no se atiene a los hechos. El "buen sentido" aconseja aqui, como en otras partes, evitar los extremos y buscar una síntesis de los aspectos positivos de la casuística y la ética situacional. La búsqueda de tal síntesis -0 , al menos, de un acercamiento- implica, por lo pronto, la admisión del conflicto básico de la vida moral, es decir, el reconocimiento de su existenecia y de su fuerza configuradora.

\section{La "ley individual"}

En conexión con este problema es importante también la posición de Georg Simmel, quien intenta individualizar la normatividad moral, oponiéndose así particularmente al "imperativo categórico" de Kant, y, de hecho, a todas las morales "universales".

La moral kantiana se basa en el concepto del "deber" (= "necesidad de una acción por respeto a la ley"), y éste alude a una razón que determina la voluntad por fundamento a priori. La ley moral, caracterizada por su apodicticidad, es válida para todo ser racional. Ahora bien, como los hombres no son seres puramente racionales, sino también "naturales" $\multimap$ sea, que su voluntad no se determina sólo por la razón, sino también por la inclinaciónesa ley moral racional ejerce una "constricción" (Nötigung) sobre la voluntad humana. ${ }^{30} \mathrm{El}$ "mandato de la razón" (= "representación de un principio

29 J. L. L. Aranguren, op. cit., pp. 275, 276. Aranguren se inclina, sin embargo, más hacia la casuistica, 0 , por lo menos, hacia una justificación de ésta frente al "desprestigio" a que se le ha sometido. Otras críticas de la "ética situacional" pueden hallarse en Dietrich von Hildebrand: Wahre Sittlichkeit und Situationsethik, Düsseldorf, Patmos-Verlag, 1957 (cf., especialmente cap. X, pp. 149 ss.), en Ulrich Lück: Das Problem der allgemeingültigen Ethik; Heidelberg-Löwen, 1963, pp. 43 ss., en Annemarie Pieper: op. cit., en n. 2o, p. 216; en Hans Reiner: Die philosophische Ethik; Heidelberg, Quelle \& Meyer, 1964, pp. 145 ss., etc. Joseph Fuchs (op. cit., en n. 18) critica la "ética situacional" en sentido extremo; pero justifica una ética situacional cristiana en la medida en que sea conciliable con la sistematización moral. Max Müller, por su parte, intenta mostrar la compatibilidad entre el reconocimiento de la individualidad situacional y la admisión de la normatividad, ya que la historia misma está constituida, según él, por los intentos, logrados o fallidos, de una representación objetiva de la libertad. Cfr. M. Müller: Erfahrung und Geschichte. Grundzüge einer Philosophie der Freiheit als transzendentale Erfahrung; Freiburg-München, K. Alber, 1971, especialmente cap. 8, pp. 261 ss. Josef Stallmach (op. cit., en n. 18) ve en la "ẹtica situacional" una forma extrema de la "ética individual". No cree que ésta sea correcta, pero admite un "ethos individual", que se desarrolla sobre el fundamento de la "ética humana", universalmente valida (cfr., pp. 49-50).

so Cfr. I. Kant: Grundlegung zur Metaphysik der Sitten, en: Werke (Akademie-Ausgabe) Bd. IV, p. 412 . 
objetivo en tanto que es constrictivo para una voluntad") se formula, según Kant, como imperativo. Los imperativos "hipotéticos" representan la necesidad práctica de una acción como medio para conseguir otra cosa que de hecho se quiere o que es posible que se quiera. El imperativo "categórico", en cambio, representa una acción por si misma, sin referencia a ningún otro fin, como objetivamente necesaria. ${ }^{31}$ Esta incondicionalidad deriva de su pura formalidad: el imperativo categórico no contiene más que la generalidad de la ley y la necesidad de la máxima de actuar por la ley, o sea, lo que él ordena es, simplemente, obrar según una máxima que pueda quererse, sin contradicción, como ley universal.

En contraposición, elabora Simmel un concepto de "ley individual" que debe entenderse como parte de su teoría de la vida y la cultura. La vida, sostiene, se trasciende a sí misma en la cultura, donde se manifiesta como "más-que-vida". Este auto-trascenderse la distingue de toda otra forma de ser. De alli proviene la formación de un orden objetivo de significaciones y vaIores en el cual el hombre encuentra tanto las reglas del juicio como los "deberes". La objetividad del "deber", sin embargo, no implica su universalidad. Contra la ley "universal" de Kant, afirma Simmel la individualidad de la ley moral, o sea, que ésta tiene su vigencia restringida a un individuo viviente determinado. ${ }^{32}$ La relación entre la vida y el deber-ser es uno de los modos de la correlación vida-forma (la "forma" puede presentarse también como "muerte", y como cualquiera de las estructuras socio-culturales o de los productos culturales objetivados). La vida se contrapone a la "forma" que - - en cuanto "no-viviente" - la limita, y, desde esta perspectiva, la correlación es, pues, antitética. Pero, desde el punto de vista de su autotrascendencia, la vida necesita de la "forma", y tiende a unificarse con ella. La "tragedia de la cultura" consiste, según Simmel, en que la vida biológica y la vida espiritual tienen exigencias distintas, que a menudo pueden hallarse en conflicto. Las obras de la cultura, que indirectamente son también formas de la vida, se coagulan en formas fijas que tratan de imponer a ésta sus propias normas. Lo mismo ocurre con las normas y los imperativos del "deber-ser" (Sollen), que, en la medida en que pertenecen a la vida "en general", no se adaptan ya a la vida "real". Pero esto no significa un divorcio entre el "deber-ser" y la "vida": "No están frente a frente vida y deber-ser, sino realidad

31 Cfr., ibid., p. 413 .

32 . El trabajo de Simmel que lleva el titulo: "Das individuelle Gesetz. Ein Versuch über das Prinzip der Ethik" apareció originariamente en la rev. Logos, Bd. IV, 19is, pp. 117-160. Fue luego reelaborado y, en parte, aumentado, al publicarse como cap. IV del libro Lebensanschautung. Vier metaphysische Kapitel, München-Leipzig, 1918 (6 ed., 1924). Aqú citaremos por la reciente edición en la selección de textos de Simmel realizada por Michael Landmann bajo el titulo: Das individuelle Gesetz. Philosophische Exkurse, Frankfurt a. M., Suhrkamp Verlag, 1968. El cap. correspondiente (tomado de la versión original) se encuentra en pp. $174^{-2} 30$. 
y deber-ser, pero ambos sobre la base de la vida, como brazos de un río, o formas de configuración de sus contenidos." ${ }^{33}$ No se trata, sin embargo, de una mera contraposición de representaciones subjetivas (de cómo se es en realidad y de cómo se "debería ser"), sino de verdaderas objetividades. Las exigencias morales son también objetivas: surgen de la totalidad de una corriente vital, y no de una relación entre contenidos conceptuales.

En su crítica a Kant, indica Simmel que éste no dice que sea el individuo como totalidad viviente quien se da a sí mismo la ley, sino que el legislador es la parte de él representada por la razón supraindividual de validez universal. Kant supone la separación de sensibilidad y razón, y, consecuentemente, afirma que la ley racional se dirige contra la sensibilidad. Para Simmel esa separación es una falsa manera de concebir lo que realmente pasa en la vida. La vida entendida como deber-ser es ley para la vida entendida como realidad. Tenemos una conciencia de lo que debemos hacer, que acompaña a la realidad de nuestra vida, sin que ese deber-hacer se presente, salvo casos raros, como una ley. Dice Simmel que "sólo el homúnculo moral de Kant, construido con puro material conceptual, apela permanentemente a la instancia suprema de una ley". ${ }^{34}$ La buena voluntad, según Simmel, no necesita de una ley que la obligue; ni siquiera sabe nada de tal ley, porque de antemano esa voluntad es buena: su vida se desarrolla en la indiferencia, tänto con respecto a su forma de "deber-ser" como a su forma de "realidad". Esas dos formas se dan originariamente como si fueran lo mismo. Cuando la reflexión las separa, el "deber-ser" puede cuajarse o cristalizarse en forma de "leyes", o sea, en una forma autónoma, independizada. Hay que tenerla en cuenta; pero, de todos modos, su importancia es secundaria. Lo primario es lo que atañe al individuo viviente. Si no se admite que hay un deber que le es absolutamente propio e intransferible, tampoco se le puede, según Simmel, atribuir responsabilidad, o sea, se desconoce el núcleo del problema ético.

La importancia de la individualidad es parte central de la filosofía simmeliana de la vida. Los seres orgánicos se caracterizan por su unidad objetiva, inmanente a ellos, y esto los distingue de los demás entes, que sólo son cosas individuales si se los reconoce como "exposición numéricamente una de un concepto". Los seres orgánicos contienen su propia entelequia, es decir, hay en ellos un centro de unidad, que los sustrae del mero concepto. Existen, desde luego, conceptos correspondientes a seres orgánicos (por ejemplo, "hombre", "león", "animal", "planta", etc., etc.); pero la esencia de éstos no se agota en tales conceptos. Lo inorgánico se unifica por medio del concepto, o sea, en las cosas inorgánicas el concepto es previo a la unidad. Lo orgánico, en cambio, es siempre un organismo, y esto significa que en ellos

33 G. Simmel, Das individuelle Gesetz, ed. cit., p. 198.

34 Ibid., p. 200. 
la unidad está dada de antemano. Lo previo es aquí la unidad real, de la que, por así decir, sale el concepto. Esto es tanto más válido en la conciencia de la propia personalidad. La acción vital no se efectúa según un sistema de conceptos, sino desde la vida misma. La crítica de Simmel a la moral kantiana destaca el hecho de que ésta se centra en la universalidad atribuida a la ley moral, la cual queda, entonces, desvinculada del individuo concreto. Es cierto que no tiene sentido ordenar a un individuo algo que éste quiere ya indefectiblemente, y en esto tiene razón Kant contra el eudemonismo, que pretendía establecer la felicidad como principio moral. Pero, a su vez, la perspectiva de Kant hace que todo lo cabalmente real quede fuera de lo moralmente exigido (a consecuencia de la separación entre "ser" y "deberser"). La ley no proviene, entonces, de lo real (el individuo), sino de lo universal (supraindividual), y, por lo mismo, no ordena al individuo real, que es contingente, sino a la razón supraindividual de la que ese individuo participa. Alli desaparecen las diferencias cualitativas entre persona y persona.

El prejuicio kantiano reside por tanto, para Simmel, en la identificación de individualidad y subjetividad. Contra ella, afirma que "lo individual no necesita ser subjetivo, ni lo objetivo ser supraindividual. El concepto decisivo es más bien: la objetividad de lo individual". ${ }^{35} \mathrm{La}$ vida individual es objetiva en su forma de "deber-ser", y esto permite hablar de "ley individual". Sólo una ley inherente al propio proceso vital del individuo agente puede presentarse a éste como imperativo moral auténtico. Aquí quedan automáticamente excluidos los motivos a los cuales con frecuencia - justificada o injustificadamente- apela el individuo para sustraerse al cumplimiento de la ley universal: ya no puede decirse que uno es distinto a los demás, o que uno no entra dentro de "ese esquema", o que lo que vale en otros casos no vale hic et nunc, etc. Aunque un determinado individuo sea (cualitativamente) distinto a los demás, no por ello puede eludir el reconocimiento de una exigencia que está justamente en su propia vida individual. El principio ético no reside (como pasaba en Kant) en la posibilidad de universalización, sino en el individuo mismo, quien por tanto no puede arrogarse para si el carácter de excepción. El antagonismo ético fundamental se da, según Simmel, entre realidad y deber-ser, y no entre individualidad y universalidad. Es un antagonismo que tiene lugar dentro de la existencia individual, conforme se advierte que la individualidad no es subjetividad ni arbitrariedad: "si la realidad - una de las formas en que vive la individualidad- posee objetividad, la otra, el deber-ser, no lo hace menos"..$^{36}$

Entiende Simmel que esta "vitalización" e "individualización" del ethos es, pues, absolutamente ajena a todo "egoísmo" y "subjetivismo", y que no representa un menoscabo, sino más bien un incremento de la rigurosidad

35 Ibid., p. 217.

36 Ibid., p. 225. 
moral. ${ }^{37}$ Con respecto a las situaciones morales concretas, advierte que la decisión se hace más difícil que cuando se la refiere a una ley universalmente válida y fijada para siempre; pero cree también que sólo así se destaca la verdadera responsabilidad del hombre. No se trata ya de un mero obrar conforme a un deber-ser general e igual para todos, sino que el deber-ser es la propia vida del individuo, considerada bajo la categoría de la idealidad. El deber-ser configura y condiciona lo "debido" en cada momento de la vida: "Ya en el volverse-debido (Gesolltwerden) de cada hacer singular reside la responsabilidad para toda nuestra historia." ${ }^{38} \mathrm{La}$ vida se presenta integramente en cada uno de los momentos de su desarrollo, y, por tanto, en cada acto del individuo. Las situaciones morales que atraviesa el individuo son múltiples y distintas, pero en todas ellas y en cada una está presente la vida de ese individuo como totalidad. Justamente porque la exigencia moral no es "fija", ni formulada de una vez para siempre, todo lo que un individuo hizo o debió hacer constituye la condición de lo que debe hacer en cada situación nueva.

La actitud de Simmel no puede, por tanto, ser calificada como "situacionista". Su síntesis de legalidad e individualidad configura, a la vez, una sintesis de lo normativo y lo situacional, que permite, por lo pronto, evitar la unilateralidad del "situacionismo" o el "casuismo". Se trata, desde luego, de una concepción discutible, contra la que se han dirigido críticas diversas. Como ejemplo de las más recientes, puede mencionarse la de Harald Delius, ${ }^{39}$ centrada a su vez en la crítica de Simmel a Kant. Delius analiza la cuestión de en qué sentido un enjuiciamiento valorativo moral es adecuado o inadecuado con respecto a su correspondiente objeto (o sea, a la conducta humana juzgada), y encuentra que el rechazo que hace Simmel de una norma moral universal imposibilita dicha adecuación. Sostiene Delius que, en consecuencia, la "ley individual" no ofrece ningún criterio. Hablar de "deber-ser moral" o de "norma moral" sólo tiene sentido cuando con ello se alude a la validez para una multiplicidad de personas, ya que tal multiplicidad está implícita en la significación de "ethos" (o mos), cercana a la del vocablo alemán Sitte (costumbre). "Moral" (sittlich) se refiere entonces a la adecuación con una determinada costumbre aprobada y practicada por muchos. La "ley individual" de Simmel, según Delius, convertiría en inadecuado todo enjuiciamiento moral de una conducta humana: lo que esencialmente se enjuicia es un "modo" o "tipo" de conducta; una conducta individual es enjuiciada sólo en la medida en que se la entiende como caso de dicho "modo".

37 Cfr. Ibid., p. 227.

38 Ibid., p. 228 (subrayado por Simmel).

39 Cfr. H. Delius, "Kategorischer Imperativ und individuelles Gesetz. Bemerkungen zu G. Simmels Kritik der Kantischen Ethik", en: H. Delius y G. Patzig (Hrsg.): Argumentationen. Festschrift für Josef König, Göttingen, Vandenhoeck \& Ruprecht, 1964; pp. 67 ss. 
Agrega que la crítica de Simmel a la ley moral kantiana estaría, además, invalidada por basarse en supuestos que desfiguran la estructura formal del objeto ético. El imperativo categórico kantiano, aunque objetable, ofrece $\cdot a l$ menos un criterio que puede pensarse como principio del enjuiciamiento, lo cual, dice Delius, falta en la concepción de Simmel, cuya "ley individual", en cambio, compartiría con el imperativo de Kant la misma vacía formalidad: ${ }^{40}$

No puede desconocerse, sin embargo, el mérito de Simmel en lo que se refiere aquí a su intento de unir o conciliar esos dos elementos básicos que, aunque en conflicto, están presentes en toda la vida moral: la normatividad y la individualidad. En todo caso, las dificultades que ofrece la individualización de la ley no son menores que las inherentes a su universalidad. Por otro lado, es preciso tener en cuenta el carácter cualitativo del individualismo simmeliano, que, como señala Michael Landmann, acerca la "ley individual" a la haecceitas de Duns Scotus: "Simmel es escotista. Une con agudeza lo objetivamente ideal, que había sido soterrado por los modernos, y lo individual, que en su lugar había sido elevado a principio. La síntesis tiene algo de inverosimil, pero justamente por ello es también tanto más grandiosa." 41 El intento de Simmel puede, en definitiva, ser objetable; pero revela una lúcida toma de conciencia del hecho fundamental: la moralidad no puede separarse de lo normativo ni de lo situacional, porque la imagen resultante, en cualquiera de esos casos, desfigura radicalmente la totalidad real. La concepción de Simmel, además, no es un hecho aislado o insólito: aparte de la ya indicada conexión con el escotismo, tiene antecedentes más cercanos y expresos en Schleiermacher y en el pensamiento romántico, y se trata d'e una idea que, de vez en cuando, encuentra todavía adeptos en la filosofía contemporánea, como en el caso de Gaetano Calabró. Éste concibe la "ley individual" como una manera de intermediación entre subjetivismo y objetivismo extremos, o sea, entre la arbitrariedad que conduce al inmoralismo y la abstracción que suprime al individuo en favor de lo general.42 Lo importante, en Simmel, es su clara distinción entre lo "individual" y lo meramente "subjetivo", y su inserción del problema moral dentro de la conflictividad básica de la cultura.

40 Cfr. H. Delius, op. cit., p. 74. J. Stallmach (op. cit., en n. 18) critica a Simmel la poca claridad del concepto "vida debida", ya que ese adjetivo no puede referirse a lo biológioo, sino que tiene que aludir a lo moralmente bueno, y no se ve entonces de dónde podría salir un "deber-ser" que en ocasiones se dirigiera contra las propias necesidades vitales (por ejemplo, en favor de la vida de otro, o de un bien común), o que incluso pudiera representar un sacrificio de la propia vida (cfr. p. 97).

41 M. Landmann, Pluralität und Antinomie. Kulturelle Grundlage seelischer Konflikte, München-Basel, E. Reinhardt, 1969, p. 297.

42 Cfr. G. Calabró: La legge individuale; Napoli, Morano, 1963, p. 7. 


\section{El terreno conflictivo de las situaciones}

Una análoga necesidad de tener en cuenta el valor de la persona individual (o sea, de la "personalidad") lleva a Nicolai Hartmann a proponer una "inversión del imperativo categórico" kantiano. El hombre, en cuanto "personalidad" - término que, como la "individualidad". de Simmel, designa lo cualitativo_, no puede querer, según Hartmann, una acción exclusivamente orientada en su posibilidad de universalización. Su "personalidad", o sea, lo que es en él más característico, más único e irrepetible ( $\mathrm{y}$ en tal medida lo distingue de los demás "individuos"), tiene que querer también, a la vez, que en su conducta haya algo propio, algo que ningún otro podría ni debería hacer en su lugar. Renunciar a ello equivale a convertirse en mero ejemplar de una especie, reemplazable por cualquier otro. La tendencia personal a que haya en el propio querer u obrar algo absolutamente único, irrepetible, incomparable, no puede, por cierto, tomar la forma de un principio consciente. Se trata - aclara Hartmann- de una tendencia que sólo se halla en el "sentimiento axiológico" (Wertgefühl). Pero in abstracto se la puede formular como ley, y se la puede oponer al "imperativo categórico" (que es también una fórmula abstracta), como una "inversión" del mismo. "Dicha ley rezaría entonces: Obra de tal manera, que la máxima de tu voluntad nunca pueda convertirse enteramente (restlos) en principio de una legislación universal. También podría decirse: no obres nunca de modo meramente esquemático, según valores universales, sino siempre al mismo tiempo (zugleich) según los valores individuales, entre los cuales está tu propio ser personal. O también: Obra, además de hacerlo según tu conciencia universal (el sentimiento axiológico moral en general), siempre también (auch) al mismo tiempo según tu conciencia privada (tu sentimiento axiológico individual)." $a 3$

Es fácil advertir que, más que una "inversión" (Umkehrung) propiamente dicha, esta fórmula representa más bien una complicación del imperativo categórico, en el que están contenidas entonces dos exigencias opuestas. Expresiones como "no enteramente", "al mismo tiempo", "también", indican la conflictividad propia de lo normativo. Hartmann destaca, como Simmel, la exigencia individual; pero, a diferencia de éste, no niega la universal, sino que la incluye como algo asimismo insoslayable. Lo que Hartmann rechaza es la exclusivización de la exigencia universal, como pasaba en el imperativo kantiano. En lugar de ello hay ahora una concomitancia de exigencias que apuntan en direcciones opuestas: el agente "debe" obrar de modo tal que su máxima pueda convertirse en "ley universal", pero nunca enteramente, porque también "debe" atender a los valores individuales; "debe" atender a su conciencia universal, pero, al mismo tiempo, a su conciencia

${ }^{43}$ N. Hartmann: Ethik, ed. cit., cap. 57 h, p. 524 . 
privada. De esta manera lo conflictivo se introduce en el núcleo mismo de la normatividad moral. Aquí juega un papel decisivo el conflicto básico que el propio Hartmann denomina "oposición axiológica cualitativa", y que tiene lugar entre la "universalidad" y la "individualidad". ${ }^{44}$ En el imperativo categórico kantiano encuentra la universalidad su expresión ética formal. Allí se destaca, según Hartmann, el valor propio de la universalidad, de modo semejante al valor del Derecho, que representa la igualdad de todos ante la ley. Pero se descuida, en cambio, el valor opuesto: el valor de la individualidad como tal: "Las mismas personas, cuya igualdad ideal ante la ley es valiosa, son, en realidad, desiguales, y no sólo en su ser natural, sino justamente también en su ser moral". ${ }^{45} \mathrm{O}$ sea, también la desigualdad de las personas constituye un valor. Como ambos valores poseen "deber-ser" - -es decir, exigen su realización- el conflicto es inevitable y aparece de hecho en todas las circunstancias de la vida.

El valor de la individualidad es también el valor propio de la "situación". Todo "esquema" desconoce en ésta su carácter esencial, y es por eso que la casuística fracasa inevitablemente: pretende prever las situaciones, que son, por esencia, imprevisibles. ${ }^{46} \mathrm{La}$ irrepetibilidad otorga a las situaciones individualidad, y las opone, desde tal perspectiva, a todos los intentos universalizadores. Podría decirse que toda situación, por tal motivo, está en conflicto con la universalidad. Pero ella se caracteriza, además, por contener en si misma algún conflicto. Hartmann dice que las situaciones "son el terreno donde crecen los conflictos y compelen a la decisión". ${ }^{47}$ Esta manera de expresarlo, sin embargo, podría llevar a suponer que hay también situaciones no conflictivas. Si la situación fuera el "terreno" -o la "base", el "piso" (Boden)- sobre el cual surgen los conflictos, éstos podrían entenderse como algo allí contingente. Serían entonces, en todo caso, un agregado, algo adherido, yuxtapuesto a la situación, y sin lo cual ésta seguiría siendo una situación. Pero, si se observa de cerca la estructura de cualquier situación, se advierte que se trata siempre de un determinado conflicto. En realidad, la situación misma no es sino la manera como la conflictividad se manifiesta concretamente, y, por tanto, una situación sin conflicto es tan poco concebible como un cuerpo sin extensión. Los conflictos no se "fundan" en las situaciones, sino más bien a la inversa: las situaciones se "fundan" en los conflictos. Hablar de "situación conflictiva" es prácticamente una redundancia, porque la conflictividad define lo situacional. Invirtiendo la expresión de Hartmann, cabría afirmar que los conflictos son el terreno donde crecen las situaciones. Son éstas, a su vez - y no aquéllos (que, en sí mismos, son meras

\footnotetext{
44 Cfr. ibid., cap. 34 , pp. 314 ss.

45 Ibid., p. 315.

46 Cfr. ibid., p. 317 .

47 Ibid. Einleitung, $\$ 3$, p. 13.
} 
estructuras oposicionales)—, las que "compelen a la decisión", y lo hacen justamente en la medida en que "crecen", es decir, en la medida en que aumentà su "urgencia" o su "gravedad".

La oposición entre individualidad y universalidad es una forma básica de conflictividad. Esto quiere decir que se trata de una estructura general, determinante de los más diversos conflictos "específicos"; o sea que, de uno u otro modo, aparece prácticamente en todas las "situaciones". La situación, caracterizada — según se vio_ por su carácter individual (irrepetible, imprevisible), es también desde otra perspectiva, un choque, una colisión concreta entre la individualidad y la universalidad. En ella se encuentran (coliden, confligen) exigencias "individuales" y exigencias "universales". El propio Hartmann lo advierte con claridad cuando se refiere a la simultánea presencia del conflicto "cualitativo" (universalidad-individualidad) y del "cuantitativo" (totalidad-individuo) en todo lo axiológico y en todo lo real. ${ }^{48}$ "Ambas antinomias -escribe_- atraviesan incólumes todo el reino de valores y están por eso incluidas en la estructura axiológica de todas las situaciones concretas de la vida." 48 Este modo de expresarse, a su vez, es consecuente con la concepción hartmanniana de un "ser-en-sí ideal" de los valores. Nos parece lícito poner reparos (lo cual, por otra parte, se ha hecho a menudo desde muy diversos puntos de vista) a dicha concepción; pero al mismo tiempo creemos que en la frase citada se mánifiesta con claridad el carácter fundante de lo conflictivo. La corrección que podría proponerse desde una actitud negadora de la "idealidad" axiológica consistiría en indicar que las formas básicas de la conflictividad son, ellas mismas, determinantes de la estructura axiológica de las situaciones concretas. En otras palabras: lo conflictivo no se "funda" en los valores, sino que los valores se "fundan" en lo conflictivo. Las situaciones tienen una "estructura axiológica" porque son, como dijimos, manifestaciones concretas de la conflictividad.

Lo propio de los auténticos conflictos, lo que constituye lo que ha dado en llamarse el carácter "trágico" de los mismos, es el hecho de que sus términos se "excluyen", pero también se "incluyen"; se "oponen", pero también se "suponen" mutuamente. Así ocurre con lo universal y lo individual. Esto es

48 Cfr., ibid., cap. 34 g, pp. 329 ss. La oposición entre "universalidad", e "individualidad" es, según Hartmann, "cualitativa", porque en ella se contraponen, como vimos, lo "igual" y lo "desigual". No se refiere a la "extensión", sino al "contenido" (cfr., ibid., p. 315). La oposición entre "totalidad" e "individuo", en cambio, es "cuantitativa": es la antinomia entre el conjunto de todos los "casos", y el caso mismo como tal. Desde cierta perspectiva, "universalidad" y "totalidad" se presuponen mutuamente, del mismo modo que lo hacen "individualidad" e "individuo". Pero, desde otra perspectiva, la "totalidad", entendida como un "caso" de orden superior, representa, a su vez, una forma de "individualidad", cualitativamente diferenciada; y el "individuo" en sentido estricto (o sea, considerado como mera expresión numérica) es "universal", porque es indiferente frente a toda "individuación" comprehensional (cfr., ibid., cap. 34 c, pp. 319 ss.).

49 Ibid., p. 330 . 
lo que permitía, por ejemplo, a Unamuno, afirmar que "nada hay más universal que lo individual, pues lo que es de cada uno lo es de todos". ${ }^{50}$ Aunque con muy distinto propósito, también Hartmann destaca esa misma relación: "la individualidad es justamente común a todos". ${ }^{51}$ Podríamos decir que las "situaciones" surgen al manifestarse una determinada incompatibilidad entre exigencias "universales" y exigencias "individuales", las cuales son, por otro lado, necesariamente complementarias.

Romano Guardini, en su interesante estudio sobre la "oposicionalidad" (término al que considera como sinónimo de "polaridad"), sostiene que ese concepto debe entenderse como "esa relación particular en la cual dos aspectos se excluyen mutuamente, $y$, sin embargo, están ligados, e incluso... se presuponen mutuamente; esa relación que aparece dentro de las respectivas configuraciones cuantitativas, cualitativas y configurativas". ${ }^{52}$ Guardini indica la existencia de todo un sistema de "oposiciones básicas" (entre las cuales se encuentra la de singularidad-totalidad y la de originalidad-regla, vinculadas con la que aquí estamos tratando), y afirma que en cada una de ellas se pone de relieve lo "paradójico" de la vida. En esa simultánea inclusión y exclusión mutuas de los términos opuestos, no se trata de "síntesis", ni de un "todo" en el que ambos lados tomen "parte", ni de una mezcla que produzca el equilibrio, sino de un "protofenómeno" (Urphänomen). Cada uno de los lados opuestos existe por sí mismo; no se deriva ni puede inferirse del otro, y hay entre ambos un límite real, y cualitativo. De uno a otro sólo puede pasarse mediante un acto específico, semejante al "salto cualitativo" de Kierkegaard. Pero ambos lados se dan siempre al mismo tiempo: cada uno sólo es pensable junto al otro. ${ }^{53}$ Si la relación fuera de pura "exclusión", se trataria de una "contradicción"; si fuera una pura "inclusión", los miembros se identificarían hasta formar una unidad. Pero la oposición es justamente la coincidencia de una inclusión y una exclusión relativas. Guardini lo ilustra mediante la imagen de dos láminas sólidas unidas entre sf por tres resortes espirales, uno de los cuales —el más fuerte, colocado en medio de los otros- está comprimido por encima de su grado de indiferencia, mientras que los dos resortes laterales se hallan extendidos también por encima de dicho estado. El total forma un "sistema", basado en el equilibrio de las tensiones opuestas del resorte central y de los dos laterales: es una unidad que se apoya en las direcciones contrapuestas de presión y contrapresión. Algo semejante ocurre con las "oposiciones" (o "polaridades"), que constituyen

50 M. de Unamuno: Del sentimiento trágico de la vida en los hombres y en los pueblos; Buenos Aires, Espasa-Calpe Argentina ("Austral", 9q ed.), 1950, p. 43.

51 N. Hartmann: Ethik, ed. cit., cap. 57 a, p. 510.

52 R. Guardini: Der Gegensatz. Versuche zu einer Philosophie des Lebendig-Konkreten; Mainz, Matthias Grünewald Verlag, 2e. Aufl., 1955, p. 3o.

53 Cfr., ibid., p. 45 . 
una "unidad de tensión" (Spannungseinheit). ${ }^{5 \pm}$ Indicaciones más o menos semejantes pueden hallarse en muchas teorías de la polaridad que han sido desarrolladas en la filosofía contemporánea. ${ }^{55}$

En la vida moral el conflicto básico entre lo universal y lo individual se manifiesta especialmente como choque entre la necesidad de la norma y la contingencia de la situación, pero, en virtud de la mencionada implicación mutua de los términos, resulta de aquí una paradoja, que podría expresarse

54 Cfr., ibid., p. go.

55 Ya para Gabriel Tarde (L'opposition universelle. Essai d'une theorie des contraires; Paris, F. Alcan, 1897) la "oposición" es una de las formas básicas de la relación entre los objetos ( $\mathrm{y}$, precisamente, la relación predominante en todos los ámbitos de la naturaleza), y consiste en una combinación de las relaciones de semejanza y diferencia (cfr., p. 1). Para A. N. Whitehead (Process and Reality, N. York, Macmillan, 1929) toda la realidad constituye un inmenso "organismo", que vincula a cada acontecimiento con los demás $\mathrm{Y}$, en definitiva, con la totalidad del proceso cósmico. Pero el universo mismo es la "autoexpresión activa de su propia variedad de oposiciones" (p. 531). Para Morris R. Cohen (Reason and Nature, Glencoe, Illinois, The Free Press Publishers, 2d, ed., 1953, pp. 165 5s.), el "principio de polaridad" permite mostrar cómo los "opuestos" se "complementan". Willmon H. Sheldon (Process and Polarity, N. York, Columbia University Press, 1944, p. 108) define la polaridad como una relación entre opuestos, cada uno de los cuales tiene "un estado parcialmente independiente, asimétrico y productivo, a causa de su cooperación". Una concepción similar aparece en Archie Bahm (Philosophy, N. York, J. Wiley \& Sons, 1953; P. 241). Heinrich Blendinger (Polarität als Weltgesetz, Stuttgart-Tübingen, $\mathbf{R}$. Wunderlich, 1947) considera la polaridad como una "ley cósmica", y reconoce dos formas fundamentales: la polaridad multiplicidad-unidad y la polaridad inmanencia-trascendencia, variaciones de una "polaridad originaria" o "protopolaridad" (Urpolarität). Con términos similares se expresa W. Rauschenberger (Das Weltgesetz der Polarität, Frankfurt a. M., Selbstverlag, 1951), quien asimismo vincula el concepto de "polaridad" con los de "complementariedad" y "correlatividad". Algunos pensadores, como Erich Przywara (Analogia entis, ze. Aufl., Einsiedeln, Johannes Verlag, 1972), enfocan la polaridad desde la perspectiva teológica; otros, como el ya citado M. Landmann (ver n. 41) y, antes que él, Erich Rothacker (Problemas de antropologia cultural, trad. S. Rovira Armengol, México, F. C. E., 1957), lo hacen preferentemente desde el punto de vista de la antropologla cultural; Louis W. Norris (Polarity. A Philosophy of Tensions among Values; Chicago, H.' Regnery, 1956) analiza los aspectos axiológicos, gnoseológicos y metafísicos de la polaridad; Walter Bloch (Polarität. Ihre Bedeutung für die Philosophie der modernen Physik, Biologie und Psychologie, Berlin, Dunkler \& Fumboldt, 1972), los referentes a la filosofía de las ciencias. Wilhelm Vershofen (Dialektik und Polarität, Wiesbaden, Necessitas Verlag, Die Weissen Hefte, 1, 1951), lo mismo que _desde una posición distinta_- John W. Buckham ("Contrapletion: The Values of Synthetic Dialectic", en: The Personalist, Univ. of Southern California, XXVI, 1945, pp. 355 ss.), estudian las relaciones entre la polaridad y la dialéctica. En el ámbito de la Psicología se destacan las obras de Albert Wellek (Die Polarität im Aufbau des Charakters; Bern, Francke, 3e. Aufl., 1966) y de Heinz-Rolf Lückert (Konfliktpsychologie; München-Basel, E. Reinhardt, 1957). Amadeo Silva-Tarouca (Philosophie der Polarität, Graz-Wien, Stiasny, 1955) adopta frente al problema una perspectiva "ontofenomenológica". La polaridad como "forma de pensar" ha sido estudiada por Hans Leisegang (Denkformen, Berlin, W. de Gruyter, 2e. Aufl., 1951, cf., pp. 317 ss.), y, más recientemente, por Paul Roubiczec (Denken in Gegensätzen; Frankfurt a. M., V. Klostermann, 1961). La lista podría continuarse indefinidamente, pues el problema ha sido abordado en sus muchos y diversos aspectos y desde todo tipo de "posiciones". Pese a las discrepancias, se coincide, por lo general, en la admisión de la simultaneidad de lo "conflictivo" y lo "complementario". 
aproximadamente diciendo que es imprescindible prever lo imprevisible; o bien, desde otro punto de vista: lo universalmente válido no debe cumplirse. Hartmann lo advierte no sólo en las antinomias "cualitativo-cuantitativas", sino también, por ejemplo, en la antinomia "modal" entre "necesidad" y "libertad", 58 o en la antinomia "relacional" entre "simplicidad" y "complejidad",57 o también al hablar de la oposición de valores como la "plenitud" y la "pureza", ${ }^{58}$ o entre la "justicia" y el "amor al prójimo", ${ }^{59}$ o entre la "veracidad" y la "mentira forzosa" (Notlüge), 60 etc. El conflicto aparece de modo claramente explícito, asimismo, en la segunda antinomia de la libertad, la "antinomia del deber-ser". ${ }^{61}$ Por eso toda la Etica hartmanniana muestra una permanente tensión entre la negación de la casuística y la afirmación del carácter normativo de los valores.

La oposición entre universalidad e individualidad, sin embargo, no debe considerarse como la única "forma básica" de lo conflictivo. Junto a ella hay por lo menos otra cuyo carácter fundamental no es inferior: la oposición entre lo "prospectivo" y lo "retrospectivo", o sea, entre las exigencias de transformación y las de conservación, entre el impulso creador y el de protección y afianzamiento, entre las virtudes de la "audacia" y la "prudencia". El problema que esto implica es complejo, porque estas dos oposiciones básicas están mutuamente relacionadas, y no es posible comprender cabalmente ninguna de ellas si no se tienen en cuenta sus relaciones. Las dos están presentes de alguna manera en toda "situación", determinando la estructura peculiar de ésta: las variaciones situacionales dependen, en definitiva, de las diferencias tensionales y del grado de complementariedad entre ambos pares de opuestos.

Samuel Ramos, refiriéndose a la personalidad entendida como un "deber", reconoce como "norma de la personalidad" la "inversión" hartmanniana del imperativo categórico, y agrega: "Sólo un prejuicio o una visión unilateral del mundo puede inducir a la creencia en una antinomia irreductible entre los valores generales y los individuales. En el cumplimiento de los deberes más comunes de la vida cabe siempre un sitio para poner una nota original". ${ }^{62}$ Pero, justamente, esa complementariedad entre lo universal y lo individual tiene relaciones con la otra forma básica de la conflictividad: la oposición entre lo "prospectivo" y lo "retrospectivo". El mismo Ramos alude, un poco más abajo, a la "gran responsabilidad histórica" que cabe a las grandes personalidades, cuya inconformidad con los valores corrientes los lleva a crear valores nuevos. Cuando éstos se objetivan en obras culturales,

56 Cfr., Hartmann, Ethik, ed. cit., cap. 32 a, pp. 299 ss.

57 Cfr., ibid., cap. 33 e, pp. 312 ss.

58 Cfr., ibid., cap. 42, pp. 407 ss.

59 Cfr., ibid., cap. 49 c, pp. $45^{2}$ ss.

60 Cfr, ibid., cap. 50 b, pp. 462 ss.

61 Cfr., ibid., caps. 72-74, pp. 686 ss.

62 S. Ramos: Hacia un nuevo humanismo; México, F. C. E., $2^{a}$ ed., 1962, p. 92. 
dice Ramos, "entran a pertenecer al dominio público y se vulgarizan". De nuevo, entonces, serán necesarios espíritus creadores de nuevos valores, y así sucesivamente: "Hay que pensar que los valores generales de hoy fueron excepcionales ayer y sólo comprendidos y amados por unos pocos. La misión de la gran personalidad es impedir que se estacione el espíritu humano. Socialmente constituye un fermento revolucionario que por el disgusto hacia los valores establecidos impulsa el movimiento de la cultura descubriendo horizontes siempre nuevos a la aspiración del hombre." ${ }^{63}$ Esto puede ser cierto; pero Ramos parece no advertir el problema que de aquí se deriva: la complementariedad entre lo universal y lo individual entraña una complicación del otro conflicto mencionado. Ramos concilia, mediante una especie de "síntesis", lo universal y lo individual. Frente al conflicto entre lo prospectivo y lo retrospectivo, en cambio, elimina este último término en favor del primero: la "retrospectividad" queda limitada a un mero proceso de "vulgarización" o "divulgación". Pero lo cierto es que "pertenecer al dominio público" y "vulgarizarse" no son conceptos idénticos (y, si lo fueran, habría que eliminar también la universalidad en favor de lo individual). "Vulgarización" tiene sentido peyorativo -alude a una deformación simplificadora y trivializadora de los bienes culturales_, en tanto que la "pertenencia al dominio público" se refiere a la verdadera vigencia de tales bienes. Hay grandes valores humanos, trabajosamente conquistados, y que siempre obligan a nuevos esfuerzos para conservarlos, frente al peligro de ser destruidos: así ocurre con la "justicia", la "democracia", la "libertad", los "derechos humanos", las obras maestras del arte, etc. Es cierto que la "movilidad" del espíritu es más visible en el sentido prospectivo, o sea, en la actividad creadora y renovadora. Pero no es menos cierto que, sin actividad "retrospectiva", el espíritu también sucumbiría, porque perdería su punto de apoyo. Lo "retrospectivo", en cuanto exigencia auténtica, no debe confundirse con la obstinación en la defensa o conservación de lo caduco. Hay desfiguraciones de lo retrospectivo, como las hay también de lo prospectivo: también lo "nuevo" puede ser artificial y trivial. Ciertos "bienes", por así decir, ya nacen vulgarizados. Otros, en cambio, jamás llegan a vulgarizarse. Hay, desde luego, muchos "valores generales de hoy" que "fueron excepcionales ayer". Pero también hay valores excepcionales de hoy que fueron generales ayer, lo mismo que hay valores que ayer y hoy fueron y son generales, $y$ valores que ayer y hoy fueron y son excepcionales. Si se advierte la necesidad del espíritu de apoyarse en lo "retrospectivo" para continuar su labor "prospectiva", puede pensarse entonces en una complementariedad entre dichos términos. Las direcciones de las correspondientes exigencias siguen siendo, no obstante, opuestas, y la relación entre ellas se conecta siempre con la relación entre los términos del otro conflicto básico. La "síntesis" entre tra63 lbid., p. 99. 
dición y creación suele dificultar la conciliación entre lo universal y lo individual.

Viene al caso recordar aquí la distinción bergsoniana entre "moral cerrada" y "moral abierta". ${ }^{64}$ " $a$ primera de éstas es aquella forma de moralidad que deriva de la "presión social" y del instinto. Subordina los intereses del individuo a los del grupo social, y tiende especialmente a la conservación y defensa de los bienes alcanzados. La "moral abierta", en cambio, tiene siempre carácter personal y se distingue por sus funciones de creación. Según Bergson, en la "moral cerrada" la presión social establece "obligaciones" de tipo estático, o sea, opuestas al cambio. Pero no todo en ella es negativo, ya que contiene el necesario principio organizador de la conducta social por medio de instituciones, costumbres, etc. Se contrapone a las fuerzas disolventes del arbitrio subjetivo, al cual suelen conducir la inteligencia y la individualidad. La "fuente" de la moral cerrada es la "presión" que la sociedad ejerce sobre el individuo. Se expresa en ella una tendencia social de autoconservación, en la que Bergson ve un producto de la evolución vital: se trataría de un recurso de la especie, para protegerse a sí misma y a los individuos que la integran. Cuando se exclusiviza, sin embargo, deriva en conformismo moral y en estancamiento. Frente a ella, la moral "abierta", propia de "santos" y de "héroes", es una moral de progreso. Tiene su "fuente" en la "emoción"; pero no en la emoción superficial, derivada de la representación, sino en la emoción profunda, creadora, que constituye más bien la causa de representaciones y pensamientos. ${ }^{65}$ Por eso, aunque deriva de lo "emocional", no puede considerársela una "moral de sentimiento", ya que posee la capacidad de cristalizarse en doctrina. Hay una transposición de la emoción a las ideas; pero éstas no surgirían sin aquella, ni tendrían fuerza para determinar la conducta si el agente no estuviera ya inclinado por la emoción originaria. ${ }^{66}$ Esta se resume en "aspiración", y su cumplimiento lleva implicito un "sentimiento de progreso", un "entusiasmo de una marcha hacia adelante". ${ }^{67}$

La contraposición de las dos morales equivale, pues, a la de lo impersonal (social) con lo personal, y a la de lo retrospectivo con lo prospectivo. El planteamiento de Bergson sirve para advertir, sin embargo, la particular complejidad de las relaciones entre las formas básicas de la conflictividad. La normatividad moral se expresa como "obligación", la cual a su vez caracteriza a la moral "cerrada". En la sociedad humana, la "obligación" desempeña un papel similar al que tiene la "necesidad" en las sociedades pura-

64 Cfr. H. Bergson: Les deux sources de la morale et de la religion; Paris, P. U. F., 49e. éd., 1946, especialm. cap. I, pp. 1-103.

65 Cfr., ibid., pp. 40 ss.

so Cf., ibid., PP. $44-45$.

67 Ibid., p. 49. 
mente naturales e instintivas, como la colmena o el hormiguero. Las obligaciones crean hábitos sociales, que determinan la conducta de los individuos. Pero, a diferencia de lo que ocurre en las sociedades animales, los individuos humanos son libres. Lo único "natural", entre ellos, es la "necesidad de la regla", 68 no la necesidad de su cumplimiento. La "obligación" implica la libertad del agente, ${ }^{69}$ y en eso se distingue del puro instinto. La moral cerra$\mathrm{da}$, de todos modos, es siempre relativa a un grupo más o menos reducido, que, por así decir, se "individualiza" frente a otros grupos extraños. Esto le impide erigirse en moral para la humanidad. La moral abierta, en cambio, pese a ejecutarse a través de personalidades excepcionales, apunta a alcanzar validez para la humanidad entera: "es humana, en lugar de ser solamente social". ${ }^{.0}$ Podría decirse, entonces, que la moral cerrada, pese a su carácter "impersonal", no es universal, sino particular, ${ }^{71}$ mientras que la abierta, siendo "personal", reviste universalidad (al menos en la intención que le da sentido). Las "almas privilegiadas", según Bergson, se sienten emparentadas con todas las almas, y en lugar de atenerse a la solidaridad establecida por la naturaleza (que se limita siempre a un determinado grupo), buscan la de la humanidad en general. No se mueven por "presión", sino por un "élan d'amour".72 Éste y aquélla, sin embargo, constituyen "dos manifestaciones complementarias de la vida, normalmente aplicada a conservar en grande la forma social que fue característica de la especie humana desde el origen, pero excepcionalmente capaz de transfigurarla por obra de individuos, cada uno de los cuales representa -como lo hubiera hecho la aparición de una nueva especie - un esfuerzo de evolución creadora". ${ }^{73}$ Ninguna de las dos morales se da de hecho en estado puro. Las morales efectivas, históricas, son siempre una mezcla de las dos, aunque, casi siempre, con el predominio de una sobre la otra. Pero, justamente, en lo que cada moral efectiva tiene de "abierta" reside su contenido de aspiración universal. Ésta determina y da sentido a la obra de las grandes personalidades individuales. En la universalidad se halla para Bergson la conciliación entre lo retrospectivo (que evita la "disolución" social) y lo prospectivo (que crea y transforma con vistas a la humanidad

68 Cfr., ibid., p. 22.

69 Cfr., ibid., p. 24 .

70 lbid, p. 31 . Bergson agrega que "entre una moral social y una moral humana la diferencia no es de grado, sino de naturaleza" (loc. cit.).

71 Fsto es comparable a algunas acotaciones de Hartmann en su tratamiento de las "oposiciones cualitativo-cuantitativas": el "tipo", o "lo típico", en cuanto particularización, representa cualitativamente un miembro intermediario entre lo "universal" y lo "individual" (cfr. Ethik, ed. cit., cap. 34 b, pp. 317 ss.), lo mismo que toda "comunidad estrecha" (ya sea una familia, un pueblo, un Estado, un partido político) constituye cuantitativamente un miembro intermediario entre la "totalidad" y el "individuo" (cfr. Ethik, ed. cit., cap. 34 h, pp. 332 ss.).

72 Cfr. Bergson, op. cit., p. 97.

73 Ibid., pp. 98-99. 
entera). Mientras en Simmel la "filosofía de la vida" se resume en una àfirmación de la individualidad como tal, en Bergson desemboca en la referencia a lo universal. No queremos, con esto, contraponer esas dos perspectivas-que, por el contrario, son fácilmente conciliables a su vez-, sino destacar la complejidad de las dos formas conflictivas básicas y de sus mutuas relaciones. Universalidad-individualidad, prospectividad-retrospectividad: en este doble enfrentamiento, y en sus mutuas e infinitas combinaciones posibles, se halla el "terreno conflictivo" de las "situaciones".

Allí se encuentra también, por otra parte, el problema permanente que la normatividad plantea a la ética. Las situaciones, como "únicas" e "irrepetibles", poseen su propia "individualidad". Lo suprasituacional, a su vez, puede entenderse como lo propio del individuo agente en todas sus situaciones posibles, y entre ambas instancias pueden surgir relaciones conflictivas. Pero, por otro lado, el individuo (lo mismo que cada situación) se enfrenta con lo supraindividual, que será también distinto si se refiere a lo "social" (la particularización del "grupo") o a la humanidad en general. ¿Dónde se halla la instancia absoluta? La conflictividad cultural lleva a Michael Landmann a afirmar una "pluralidad de los absolutos","4 denunciando como prejuiciosa la identificación tradicional entre pluralismo y relativismo. Las diferencias y las variaciones entre las diversas morales, o entre los diversos estilos artísticos, etc., no tienen por qué ser entendidas como productos del capricho o del "error" (como si sólo una moral o un estilo pudieran reclamar para sí el carácter "absoluto"), ni hay por qué derivar de allí una relativización general de toda la cultura, del mismo modo que la multiplicidad de idiomas diferentes no impide que cada uno de ellos alcance su propia perfección. Esta solución propuesta por Landmann, sin èmbargo, sólo toca parcialmente al problema que aquí estamos tratando. Esa "pluralidad de absolutos" puede, quizá, referirse a estructuras normativas correspondientes a "pueblos" u otras comunidades culturales; pero, ¿hasta dónde se extiende? ¿Hay también normas morales absolutas para agrupaciones humanas más reducidas (para una familia, por ejemplo)? ¿Las hay para cada individuo? ¿Y qué decir entonces de cada situación? Si también a ésta se la "absolutiza", se cae de nuevo en el relativismo: la afirmación de una "infinidad de absolutos", o sea, la atomización de lo absoluto, quitaria todo sentido a la distinción entre los términos "absoluto" y "relativo". La limitación de la vigencia de una norma -a lo cual se aludió al comienzo de este trabajo- a la última unidad indivisible de la vida moral deja de ser "limitación" y se convierte en "negación" de la vigencia.

Pero, por otro lado, cabe también preguntar qué es eso de "última unidad indivisible" de lo moral. ¿Qué extensión y qué comprehensión tiene el

74 Cfr. M. Landmann: Der Mensch als Schöpfer und Geschöpf der Kultur; MünchenBasel, E. Reinhardt, 1961, pp. 54 ss. 
concepto de "hic et nunc"? El problema de los límites de la vigencia de las normas se complica con el de los límites de las "situaciones". ¿Dónde y cuándo comienza, y dónde y cuándo acaba una situación? ¿Es realmente lícito atomizar lo moral? ¿No está más bien toda situación referida siempre a un contexto más amplio, de modo tal que unas situaciones más "amplias" abarcan, por así decir, a otras más "reducidas"? Pero quizá sea, en suma, imposible determinar cuáles son las más reducidas. Además, si éstas se entienden por su referencia a otras más "amplias", acaso sea imposible también determinar la situación "máxima", la que abarcaria a todas las demás (a menos que se convenga en llamar "situación" a la totalidad de la historia universal). Si la norma tiene una vigencia "limitada" a tal situación "máxima", habrá que conceder que ella es "situacional" y, a la vez, que posee "universalidad".

Desde luego, no pueden continuarse los razonamientos por esa via. Este tipo de consideraciones sólo sirve para mostrar que es necesario admitir una correlatividad entre los conceptos de "normatividad" y "situación". Pero esto no en un sentido "casuístico", de "catalogación" de todas las situaciones posibles, sino teniendo en cuenta el sentido de "situación" justamente como el encuentro de lo universal y lo individual. Por el principio leibniziano de la "identidad de los indiscernibles" se sabe que es imposible, por ejemplo, que haya dos hojas absolutamente iguales. Cada hoja tiene por lo menos algún minúsculo detalle que la distingue de todas las demás. Pero no menos cierto es que posee elementos que permiten compararla con las demás, y que hacen de ella precisamente una hoja, y no una piedra ni un insecto ni un pez. Del mismo modo, cada situación tiene elementos absolutamente propios, que la hacen "única", "individual", "irrepetible"; pero también, a la vez, elementos comunes a todas las demás situaciones, que hacen de ella precisamente una "situación". Y ocurre que, además, estos elementos confligen con aquellos. Cada situación surge de ese choque, es decir, de un choque concreto entre exigencias "individuales" y exigencias "universales" (como también, a la vez, del choque entre exigencias prospectivas y exigencias retrospectivas, el cual, como vimos, complica aún más su estructura).

Una investigación más profunda del problema requeriría, por tanto, indagar el origen de esa doble conflictividad básica, lo cual representa, desde luego, una cuestión mucho más ardua. Aqứ sólo puede dejársela indicada; pero acaso no sea ilícito conjeturar que ese origen debe hallarse en la condición misma del ser humano. El hombre, en virtud de su libertad, constituye una encrucijada de exigencias contrapuestas. La vida humana en general, y la vida moral en particular, discurre entre requerimientos cuyas realizaciones se excluyen mutuamente. Tales requerimientos, tales "exigencias", no tendrían sentido si sus contenidos se realizaran por sf solos, o si estuvieran ya realizados. Son, por tanto, testimonio de lo aún no hecho, de lo gue falta. El 
hombre tiene siempre ante sí un vacio por llenar, una carencia que necesita ser compensada. La antropología filosófica contemporánea ${ }^{75}$ ha puesto suficientemente de relieve esta característica condición deficitaria, que permite, en definitiva, explicar el porqué de la cultura y su desarrollo. En la cultura el hombre va haciéndose a si mismo, porque no está definitivamente "hecho" por la naturaleza. Su carencia es, pues, natural, biológica, y requiere ser compensada por ese recurso extranatural que es la cultura. Podemos, entonces, admitir con Bergson que toda moral "es de esencia biológica" ${ }^{76}$; pero es preciso añadir que surge, justamente, de una carencia biológica. Toda la cultura proviene, sin duda — como lo ve claramente Simmel-, de la vida. Se trata de una auto-trascendencia, sin embargo. La vida se trasciende a sí misma, se hace "más-que-vida". ¿Cómo explicar este hecho sino admitiendo la aparición de una insuficiencia radical que logró, no obstante, repararse? Las insuficiencias vitales no son, desde luego, una novedad en la naturaleza. Por regla general, si ellas se presentan en el individuo, aceleran en éste la muerte; si afectan a una especie, conducen a su extinción. En la especie humana, en cambio, aparece lo excepcional, lo inédito: el recurso para sobrevivir a la insuficiencia biológica. Pero esta reparación no es una vuelta al equilibrio vital, sino, por el contrario, la entrada en un desequilibrio perpetuo: la cultura prolonga, en todas sus manifestaciones, el conflicto originario. Sus múltiples transfiguraciones son, en el fondo, transfiguraciones y nuevas versiones de dicho conflicto, o sea, del enfrentamiento de un ser biologicamente defectuoso con la naturaleza que lo limita. El impulso creador emana de la vida cuando los límites se han hecho conscientes: la experiencia de la insatisfacción vital es el resorte de la cultura, y en ésta se reproduce y complica, porque las obras culturales, aunque permiten sobrevivir, reducen todavía más el ya escaso vigor puramente natural: la cultura es creación de compensaciones, pero también, simultáneamente, producción de nuevos menesteres.

Los dos conflictos básicos se originarian, entonces, en la condición biológicamente deficitaria del hombre, y serían expresión directa de la estructura conflictiva de la cultura. El impulso creador tropieza necesariamente con el impulso protector de lo creado; la originalidad se opone a la norma. Ninguno de esos puntos cardinales puede eliminarse, porque, aunque sus relaciones tengan tendencia a engendrar conflictos, son también complementarios. Ellos determinan asimismo el carácter antinómico de las "situaciones" morales. Éstas no pueden preverse por medio de una "tipificación" (como quiere el casuismo), pero tampoco pueden desprenderse de las normas

75 Cfr. Max Scheler, El puesto del hombre en el cosmos; trad. J. Gaos; Buenos Aires, Losada, 1943. Helmut Plessner, Die Stufen des Organischen und der Mensch; Berlin, 1928. De especial interés en este respecto es la obra de Arnold Gehlen: Der Mensch. Seine Natur und seine Stellung in der Welt; Bonn, Athenäum Verlag, 6e. Aufl., 1969.

76 H. Bergson, op. cit., p. 10g. 
(como pretende el situacionismo), porque tanto en uno como en otro caso se amputa la mitad de su contenido.

Gusdorf indica que la unidad personal no se alcanza sin una referencia a lo universal. Simmel rechaza lo universal, pero su "ley individual" es una afirmación expresa de la objetividad normativa. Hay incluso pensadores que, como Polin, niegan la objetividad, pero no renuncian a la norma: Polin sostiene que una norma concreta de acción sólo se asegura desde un "subjetivismo axiológico"."7 Hartmann muestra claramente la simultaneidad de las contrapuestas exigencias universales e individuales en lo moral. Bergson permite apreciar la complejidad de las interrelaciones entre las oposiciones básicas, y muestra, lo mismo que Simmel, Landmann, Gehlen y muchos otros, la vinculación entre la moral y la vida. Todos estos elementos - y no son, por supuesto, los únicos - han de tenerse en cuenta si se aspira a comprender la paradoja de las situaciones, que es, al mismo tiempo, la paradoja de la normatividad.

Rrcardo MaLIANDI

Consejo Nactonal de Investigaciones Cientificas y Téchicas Buenos ATres

${ }^{77}$ Cfr. R. Polin, "Subjectivisme des valeurs et réflexion morale" (artículo cit., en n. 24). 